\title{
PENGARUH TEKNIK BIBLIOTERAPI TERHADAP PERENCANAAN KARIR SISWA KELAS XI DI SMA NEGERI 1 TARAKAN TAHUN PELAJARAN 2018/2019
}

\author{
Tiya Apriliana, Urotul Aliyah \\ Fakultas Keguruan dan Ilmu Pendidikan, Universitas Borneo Tarakan \\ tiya06@gmail.com
}

\begin{abstract}
This research aims to determine the effect of bibliotherapy techniques on career planning of students in SMA Negeri 1 Tarakan. This research used quantitative research design through a quasi-experimental approach. The independent variable was bibliotherapy technique and the dependent variabel was the students' career planning. The population in this research were 216 students and used purposive sampling of 20 students at SMA Negeri 1 Tarakan as the technique of sampling. While for the instrument, this research used student career planning scale with the attitude measurement scale. In this research, descriptive statiscal analysis and inferensial were used as the data analysis.

Based on the results of data analysis and discussion of research results, it can be concluded that the career planning of class XI students at Tarakan 1 Public High School 2018/2019 Academic Year before being treated (pretest) the average score of 105.90 which means the average student has a plan medium career. After being given treatment (posttest) the results of the average score of 124.10, which means that most of the students have experienced an improvement in their career planning. This is reinforced by the results of the analysis shows the value of significance level of 0.000 which means smaller than the significance level of 5\%. So it can be concluded that there is an influence of bibliotherapy techniques on the career planning of class XI students at SMA Negeri 1 Tarakan in the 2018/2019 school year.
\end{abstract}

Keywords: Bibliotherapy Technique, Student Career Planning

\section{PENDAHULUAN}

Remaja berasal dari Bahasa Latin adolescene berarti tumbuh atau tumbuh menjadi dewasa. Garis pemisah antara awal dan akhir masa remaja terletak kira-kira di sekitar usia tujuh belas tahun, usia rata-rata remaja memasuki sekolah menengah tingkat atas (Hurlock, 2003:206). Pada masa remaja ini, mereka dituntut untuk menjalankan tugastugas perkembangannya.

Menurut Havighurst persiapan mandiri secara ekonomis, pemilihan dan pelatihan jabatan merupakan salah satu tugas perkembangan yang harus dilalui selama masa remaja (dalam Panuju, 2005:24). Remaja yang memasuki Sekolah Menengah Atas (SMA) merupakan siswa yang berada pada tahap persiapan karir. Sebelum siswa mempersiapkan karirnya, perlu terlebih dahulu merencanakan karirbagi masa depannya setelah tamat sekolah. Pada masa ini, remaja dituntut untuk berpikir dan mengambil keputusan tentang masa depan.

Menurut Winkel (2013:685), kunci bagi perencanaan yang matang dan keputusan yang bijaksana terletak dalam mengelola informasi tentang diri sendiri dan tentang lingkungan hidupnya. Hal ini sangatlah penting bagi siswa untuk memudahkannya dalam menentukan arah studi yang akan diambil. Apabila siswa tidak berpikir serius tentang masa depannya dan kurang berusaha membuat pilihan-pilihan secara bertanggung jawab, menciptakan bagi dirinya sendiri suatu masa depan yang sudah suram sebelum masa depan itu tiba.

Berdasarkan hasil observasi di SMA Negeri 1 Tarakan pada tanggal 21 Maret 2018 diperoleh fakta bahwa ada beberapa masalah siswa yang berkaitan dengan bidang karirnya yaitu: 1) kurangnya memahami tentang bagaimana cara memilih pekerjaan atau studi lanjut; 2) cemas kalau menjadi penganggur 
setelah menyelesaikan pendidikan; 3) bingung belum memiliki cita-cita. Jika tidak ada upaya untuk memperbaiki hal tersebut, jelas akan berdampak buruk pada sumber daya manusia. Hal ini akan menghambat tujuan dari perkembangan sumber daya manusia sebagai wujud dari pembangunan seperti bertambahnya jumlahpengangguran.

Melihat situasi ini maka perlu adanya usaha positif untuk mengatasi masalah yaitu melalui teknik biblioterapi.Menurut Abdullah (Erford, 2016:287), membaca sebuah buku dan mampu mengidentifikasikan diri dengan seorang tokoh, klien dapat "belajar dari orang lain bagaimana cara mengatasi masalahnya" dan "melepaskan emosi-emosi," mencapai

arah baru dalam kehidupan, dan mengeksplorasi cara baru dalam berinteraksi". Teknik biblioterapi dapat digunakan sebagai suatu pembentukan kehidupan individu melalui pertumbuhan kesadaran.

Berdasarkan latar belakang di atas, peneliti tertarik untuk melakukan penelitian dengan judul "Pengaruh Teknik Biblioterapi Terhadap Perencanaan Karir Siswa di SMA Negeri 1 Tarakan"

\section{METODE PENELITIAN}

Metode penelitian ini, menggunakan desain Non equivalent Control Group Design, dalam desain jenis ini sampel tidak dapat diambil secara random. Pada desain ini kelompok eksperimen di beri pretest dan posttest kemudian dibandingkan dengan hasil pretest dan posttest kelompok kontrol. Penelitian ini dilaksanakan di SMA Negeri 1 Tarakan selama bulan Juli-Agustus 2018.

\section{POPULASI DAN SAMPEL PENELITIAN}

Adapun untuk keperluan penelitian ini yang menjadi populasinya adalah seluruh siswa kelas XI MIPA dan menggunakan teknik purposive sampling sebagai teknik pengambilan sampel berdasarkan kriteriakriteria tertentu.

\section{TEKNIK ANALISIS DATA}

Teknik pengumpulan data yang digunakan dalam penelitian ini adalah skala perencanaan karir siswa. Data dianalisis dengan menggunakan analisis deskriptif dan inferensial.

\section{HASIL DAN PEMBAHASAN}

Hasil penelitian menunjukkan bahwa pelaksanaan konseling kelompok dengan teknik biblioterapi memperlihatkan perubahan. Sebelum pemberian perlakuan skor perencanaan karir berada dikategori rendah, sedang atau tinggi dengan ratarata 105.90 dan setelah perlakuan menjadi tinggi atau sangat tinggi dengan rata-rata 124.10 .

Kemudian dengan adanya diskusi setiap anggota kelompok memberikan kesempatan kepada setiap siswa dapat bertukan pemahaman, pendapat, pikiran, dan motivasi baik antara siswa dengan siswa maupun siswa itu sendiri.

Hasil diskusi juga membuat siswa dapat mengidentifikasi diri dengan salah satu tokoh dalam buku bacaan yang telah dibaca oleh siswa. Pernyataan ini diperkuat dengan pendapat Abdullah (dalam Erford, 2016:287), membaca sebuah buku dan mampu mengidentifikasikan diri dengan seorang tokoh, klien dapat "belajar dari orang lain bagaimana cara mengatasi masalahnya" dan "melepaskan emosiemosi," mencapai arah baru dalam kehidupan, dan mengeksplorasi cara baru dalam berinteraksi". Kemudian, dari proses diskusi masalah juga siswa mendapatkan beberapa solusi-solusi yang digunakan siswa dalam meningkatkan motivasi diri siswa, dan ketahanan emosi dalam menghadapi masalah. Kemudian, berdasarkan hasil uji hipotesis pada kelompok kontrol dan kelompok eksperimen dengan membandingkan hasil sebelum diberikan perlakuan (pretest) dan setelah diberikan perlakuan (posttest) hipotesis diterima, yang berarti bahwa ada pengaruh teknik biblioterapi terhadap perencanaan siswa kelas XI di SMA Negeri 1 Tarakan Tahun Pelajaran 2018/2019.

\section{KESIMPULAN}

Berdasarkan hasil analisis data dan pembahasan hasil penelitian, dapat ditarik suatu kesimpulan bahwa adanya kesadaran siswa akan pemahaman dirinya sendiri, pentingnya memiliki cita-cita, dan pemahaman informasi terkait studi lanjut dan pekerjaan/jabatan. Selain itu siswa dapat mengidentifikasi diri dengan salah satu tokoh dalam buku bacaan yang telah dibaca oleh siswa guna mendapatkan beberapa solusisolusi yang digunakan siswa dalam meningkatkan motivasi diri siswa, dan ketahanan emosi dalam menghadapi masalah terkait perencanaan karirnya.Kemudian, 
berdasarkan hasil uji hipotesis pada kelompok kontrol dan kelompok eksperimen dengan membandingkan hasil sebelum diberikan perlakuan (pretest) dan setelah diberikan perlakuan (posttest) hipotesis diterima, yang berarti bahwa ada pengaruh teknik biblioterapi terhadap perencanaan siswa kelas XI di SMA Negeri 1 Tarakan Tahun Pelajaran 2018/2019.

\section{DAFTAR PUSTAKA}

Arikunto. Suharsimi. 2013. Prosedur Penelitian Suatu Pendekatan Praktik. Jakarta: Rineka Cipta.

Atmaja, T. Twi. 2014. Upaya Meningkatkan Perencanaan karir Siswa Melalui Bimbingan Karir dengan Penggunaan Media Modul. Psikopedagogia. Vol. 3, No. 2: 62.

Azwar, Syaifuddin. 2014. Penyusunan Skala Psikologi. Yogyakarta: Pustaka Pelajar.

Eliasa, Iswanti 2014. Bibliotherapy With The Career Topic To Increase The Student's Career Motivation of Guidance And Counseling. Procedia- Social and Behavioral Sciences. ISSN 114 434438.

Erford T. Breadley. 2016. 40 Teknik yang Harus Diketahui Setiap Konselor. Yogyakarta: Pustaka Pelajar.

Falentini Y Febry., Taufik., \& Mudjiran. 2013. Usaha yang dilakukan siswa dalam menentukan arah pilihan karir dan hambatan-hambatan yang ditemui (Studi Desktiptif terhadap Siswa SMA N 3 Payakumbuh).Jurnal Ilmiah Konseling. Vol 2. No.1:310-316.

Hurlock, Elizabeth. B. 2003. Psikologi Perkembangan. Jakarta: PT. Erlangga.

Komara, B. Indra. 2016. Hubungan Antara Kepercayaan Diri dengan Prestasi Belajar dan Perencanaan Karir Siswa. Psikopedagogia. Vol 5, N0.1.

Panuju, Panut., \& Umami Ida. 2005.Psikologi Remaja. Yogyakarta: PT. Tiara Wacana Yogya.

Prasetyo,Bambang.,\&Jannah M.Lina. 2016. Metode PenelitianKuantitatif.Jakarta: PT. Raja Grafindo Persada.

Sugiyono. 2015.2 Metode PenelitianPendidikan. Bandung: Alfabeta.

Suherman, Uman. 2009. Konseling Karir SepanjangRentang Kehidupan. Bandung:UPI.
TrihantoroArdo.,Hidayat.R.Dede., \& Chanum Indira. 2016. Pengaruh Teknik Biblioterapiuntuk mengubah KonsepDiri Siswa. Jurnal Bimbingan Konseling:Insight 5(1).

Winkel W.S., \& Sri Hastuti. 2013. Bimbingan dan Konseling di Institusi Pendidikan. Yogyakarta: Media Abadi. 